\title{
CRISE E CONSTRUÇÃO DE UMA NOVA ORDEM TERRITORIAL NO ESTADO DO RIO DE JANEIRO
}

\author{
JACOB BINSZTOK \\ Universidade Federal Fluminense
}

\section{A conjuntura sócio-econômica fluminense}

O quadro econômico do Estado do Rio de Janeiro é bastante complexo, pois trata-se de uma unidade da federação colocada em segundo lugar nos indicadores de produto per capita e atividade industrial e, por outro, pela presença de indicadores que refletem uma longa e grave crise de perda de substância econômica. Procurando melhor classificar esta situação, procedemos ao exame de algumas informações básicas, como: produto interno bruto; renda per capita; participação setorial; índice do produto real; taxa de incremento e volume de vendas de empresas privadas e estatais. Tais informações foram centralizadas a partir dos anos 70, 80 e 90, revelando a evolução recente da economia fluminense, comportamentos setoriais e movimentos de reestruturação visando uma nova inserção no contexto nacional.

$\mathrm{Na}$ análise das informações referentes ao produto interno bruto e da renda per capita do Brasil e do Estado do Rio de Janeiro, constatamos que os dados da Tabela 1 demonstram o aumento gradual do PIB estadual, com elevação da renda per capita, nas décadas de 80/90, contrariando tendências prognosticadas por pesquisadores, que denominaram o período de "década perdida", em função da estagnação e conseqüente descenso registrado nos indicadores de renda per capita nacionais. 


\section{TABELA 1}

BRASIL E ESTADO DO RIO DE JANEIRO PRODUTO INTERNO BRUTO E RENDA PER CAPITA VALORES ABSOLUTOS EM DÓLARES (1970-1994)

\begin{tabular}{|c|c|c|c|c|c|c|}
\hline \multirow[t]{2}{*}{ ANOS } & \multicolumn{3}{|c|}{ BRASIL } & \multicolumn{3}{|c|}{ RIO DE JANEIRO } \\
\hline & $\begin{array}{l}\text { PIB (milhões } \\
\text { de dólares) }\end{array}$ & $\begin{array}{c}\text { População } \\
\text { (hab.) }\end{array}$ & $\begin{array}{l}\text { Renda per } \\
\text { capita US\$ }\end{array}$ & $\begin{array}{l}\text { PIB (milhões } \\
\text { de dólares) }\end{array}$ & $\begin{array}{c}\text { População } \\
\text { (hab.) }\end{array}$ & $\begin{array}{l}\text { Renda per } \\
\text { capita US\$ }\end{array}$ \\
\hline 1970 & 33.027 & 93.139 .037 & 355 & 5.506 & 8.994.802 & 612 \\
\hline 1975 & 105.962 & 105.279 .615 & 1.066 & 16.291 & 10.077 .946 & 1.617 \\
\hline 1980 & 233.333 & 119.002 .706 & 1.961 & 33.081 & 11.291 .520 & 2.930 \\
\hline 1985 & 327.619 & 130.964 .997 & 2.502 & 40.017 & 11.946 .900 & 3.350 \\
\hline 1990 & 376.085 & 146.917 .459 & 2.560 & 40.949 & 12.783 .761 & 3.203 \\
\hline 1994 & 395.478 & 155.608 .189 & 2.541 & 49.514 & 13.223 .924 & 3.744 \\
\hline
\end{tabular}

Fonte: EBAP/FGV, 1995

Organização: Jacob Binsztok

A Tabela 2 mostra a participação do Estado do Rio de Janeiro no produto interno bruto nacional, perfazendo cerca de $11 \%$ do total, com US\$ 40 bilhões num montante estimado de US\$ 375 bilhões, correspondente ao PIB total do país.

\section{TABELA 2}

PARTICIPAÇÃO DO ESTADO DO RIO DE JANEIRO NO PRODUTO INTERNO BRUTO DO BRASIL POR SETORES DA ECONOMIA - 1990

\begin{tabular}{lcccc}
\hline & \multicolumn{2}{c}{ BRASIL } & \multicolumn{2}{c}{ Rio de Janeiro } \\
\hline Setores & $\begin{array}{c}\text { US\$ (Milhões } \\
\text { de Dólares) }\end{array}$ & $\%$ & $\begin{array}{c}\text { US\$ (Milhões } \\
\text { de Dólares) }\end{array}$ & $\%$ \\
\hline Agricultura & 42.160 & 11,21 & 332 & 0,81 \\
Indústria & 133.060 & 35,38 & 12.772 & 31,19 \\
Serviços & 144.358 & 38,65 & 21.072 & 51,46 \\
Comércio & 55.511 & 14,76 & 6.773 & 16,54 \\
\hline Total & 376.089 & 100 & 40.949 & 100 \\
\hline
\end{tabular}

Fonte: FBAP/FGV, 1995.

Organização: Jacob Binsztok

$\mathrm{Na}$ análise da distribuição do PIB por setores, destacamos a importância dos serviços para a economia fluminense que, estimado em 21 bilhões de dólares, atingiu 51,46\% do PIB estadual, colocando-se acima da média nacional, que regis- 
tra $37 \%$ do PIB brasileiro. Os setores industrial e comercial com, respectivamente, $31 \%$, $19 \%$ e $16 \%$ do PIB estadual, acompanharam, em linhas gerais, a dinâmica dos indicadores nacionais. O setor agrícola, contabilizando US\$ 332 milhões, correspondendo a $0,82 \%$ do PIB, distante das médias nacionais, foi apontado como um dos emblemas da estagnação econômica do Estado do Rio de Janeiro.

A Tabela 3 revela no período 80/90, as oscilações do Produto Real do Estado do Rio de Janeiro.

\section{TABELA 3}

ESTADO DO RIO DE JANEIRO E BRASIL

ÍNDICE DO PRODUTO REAL, SEGUNDO SETOR - 1980-1990 (Base: 1980 / 100)

\begin{tabular}{|c|c|c|c|c|c|c|c|c|c|c|}
\hline \multirow[t]{2}{*}{ ANOS } & \multicolumn{2}{|c|}{ AGRICULTURA } & \multicolumn{2}{|c|}{ INDÚSTRIA } & \multicolumn{2}{|c|}{ COMÉRCIO } & \multicolumn{4}{|c|}{$\begin{array}{l}\text { TRANSPORTES E PRODUTO } \\
\text { COMUNICAÇÕES REAL (Total) }\end{array}$} \\
\hline & RJ & BRASIL & RJ & BRASIL & RJ & BRASIL & RJ & BRASIL & RJ & BRASIL \\
\hline 1980 & 100,0 & 100,0 & 100,0 & 100,0 & 100,0 & 100,0 & 100,0 & 100,0 & 100,0 & 100,0 \\
\hline 1981 & 104,3 & 106,4 & 95,9 & 94,5 & 92,0 & 97,2 & 97,1 & 100,2 & 95,0 & 98,4 \\
\hline 1982 & 105,9 & 103,7 & 97,5 & 95,1 & 95,9 & 98,1 & 99,0 & 105,8 & 97,5 & 99,3 \\
\hline 1983 & 107,3 & 106,0 & 88,2 & 88,6 & 83,5 & 94,7 & 98,8 & 105,9 & 88,2 & 96,1 \\
\hline 1984 & 97,0 & 110,5 & 87,5 & 93,8 & 82,1 & 97,5 & 102,1 & 112,8 & 87,3 & 100,4 \\
\hline 1986 & 100,37 & 111,68 & 114,88 & 99,06 & 123,06 & 108,74 & 103,55 & 121,09 & 144,61 & 113,36 \\
\hline 1987 & 96,15 & 128,40 & 114,66 & 110,71 & 111,68 & 111,51 & 102,65 & 126,2 & 112,39 & 117,40 \\
\hline 1988 & 100,27 & 129,48 & 114,82 & 111,87 & 110,73 & 108,62 & 100,47 & 131,96 & 112,22 & 117,32 \\
\hline 1989 & 104,24 & 133,17 & 119,56 & 108,97 & 111,47 & 111,94 & 106,23 & 136,42 & 116,37 & 121,16 \\
\hline 1990 & 87,39 & 128,21 & 106,95 & 112,13 & 99,21 & 104,84 & 104,99 & 132,60 & 104,91 & 115,85 \\
\hline
\end{tabular}

Fonte: FIBGE - 1980/90

A leitura das referidas informações confirma o declínio do setor agrícola fluminense em relação aos índices nacionais. A indústria e o comércio, porém, não apresentaram nenhum período de declínio prolongado, acompanhando em linhas gerais a performance do país, com exceção, do boom ocorrido em 1986, proporcionado pelo advento do Plano Cruzado, que colocou os respectivos setores e o produto real do estado numa posição bastante acima dos indicadores nacionais.

A Tabela 4, apresentando dados referentes ao produto real e à taxa de incremento da última década, revela novos ângulos do problema.

A análise das informações mostrou que, no período de 1975/78, o estado registrou ligeira recuperação, chegando a ter incremento do produto real acima do conjunto do país. Tal crescimento, resultou acima de tudo, de iniciativas pontuais promovidas pelo regime militar interessado em consolidar rapidamente o governo Faria Lima, encarregado de executar de forma autoritária o processo de fusão entre os Estados do Rio de Janeiro e Guanabara. Todavia, essa vantagem representou simples variação conjuntural, não alterando a tendência declinante, conforme 


\section{TABELA 4}

ESTADO DO RIO DE JANEIRO E BRASIL

PRODUTO REAL - TAXA DE INCREMENTO, POR SETOR - 1975-1985

\begin{tabular}{|c|c|c|c|c|c|c|}
\hline \multirow{3}{*}{ SETOR } & \multicolumn{6}{|c|}{ PERÍODO } \\
\hline & \multicolumn{2}{|c|}{1975 - 1978} & \multicolumn{2}{|c|}{1979 - 1982} & \multicolumn{2}{|c|}{$1983-1985$} \\
\hline & RJ & BRASIL & RJ & BRASIL & RJ & BRASIL \\
\hline Agricultura & 2,9 & 3,8 & 3,0 & 3,3 & $-2,7$ & 6,5 \\
\hline Indústria & 8,7 & 7,8 & 0,4 & 0,8 & 1,8 & 7,4 \\
\hline Comércio & 7,3 & 7,4 & $-2,8$ & 1,6 & 3,5 & 5,8 \\
\hline Transportes e Comunicações & 7,0 & 11,1 & 0,9 & 5,2 & 4,8 & 6,7 \\
\hline Produto Real (Total) & 8,1 & 6,8 & $-0,4$ & 2,1 & 2,5 & 6,4 \\
\hline
\end{tabular}

Fonte: FGV, FAPERJ e CIES/SECPLAN

demonstram os dados para 1979/82 e 1983/85. Nestes dois períodos, o incremento do produto real fluminense volta a ser largamente superado pela média nacional.

Com respeito à agricultura, os dados reafirmaram as informações do produto real bruto, mostrando as cíclicas variações do setor, alternando períodos de relativo equilíbrio entre 75/82, com a presença de indicadores negativos, nos anos de $83 / 85$.

\section{Crise e uma nova ordem territorial no Estado do Rio de Janeiro}

As causas normalmente assinaladas para justificar a situação anômala do Rio de Janeiro, estado que vem apresentando forte e prolongada tendência ao declínio relativo, tendem a apontar no sentido de que o cerne do problema se encontra na longa e artificial separação entre a cidade do Rio de Janeiro e sua região polarizada.

Nesta linha, as causas apontadas para o esvaziamento do Rio de Janeiro são as seguintes:

a) longa e artificial separação entre RJ - capital e RJ - estado;

b) mentalidade espacial das elites locais, gerada por essa separação;

c) mudança da capital federal sem adequadas medidas compensatórias;

d) fusão RJ-GB pautada pelo autoritarismo e sem as necessárias medidas acautelatórias.

No contexto brasileiro as capitais estaduais tendem geralmente a monopolizar parcelas significativas da atividade econômica da área, gerando impostos que 
teoricamente teriam que ser aplicados na totalidade do território. Assim, no caso específico do conjunto município do Rio de Janeiro e Estado do Rio de Janeiro coube ao primeiro, por raízes históricas e geográficas, exercer o papel de principal pólo econômico da região, inibindo o crescimento de Niterói, antiga capital política do estado e subordinando-a paulatinamente à função de cidade-dormitório.

Prosseguindo constata-se, por observação direta, que os tributos estaduais recolhidos no município do Rio de Janeiro, por motivos de manipulação política, não conseguem ser aplicados de forma racional, na melhoria da infra-estrutura, nem tampouco no aperfeiçoamento da vida de relações que caracteriza a cidade e sua região, representada pela área metropolitana e pelo interior do estado. Logo, o corolário mais importante desta questão é de que a região Metropolitana do Rio de Janeiro não poderia concorrer com o $\mathrm{ABCD}$ paulista e outras áreas na disputa pela implantação das indústrias de bens de capital e consumo durável, que passaram a se expandir no país a partir dos anos cinqüenta/sessenta.

Com respeito à elaboração de políticas públicas no Brasil, é relevante salientar o papel desempenhado pelos estudos do geógrafo Bernard Kayser, nos compêndios da denominada Geografia Ativa, no final dos anos 60, recomendando a utilização da "região geográfica" como objeto de intervenção governamental, com grande repercussão entre os geógrafos do IBGE e os economistas do recém criado IPEA (Instituto de Pesquisa Econômica e Aplicada). A intervenção governamental, caracterizar-se-ia pela adoção de programas de desenvolvimento direcionados para a exploração do potencial de áreas consideradas "deprimidas", tornando-as organizadas, segundo os padrões das regiões mais desenvolvidas.

Nesta linha é importante alertar para o fato de que, em países marcados por elevado grau de autoritarismo, como no caso brasileiro, os programas de desenvolvimento, principalmente no setor agrícola, não são efetivamente comandados pelo governo e sim pela "ideologia de Estado" ou, conforme salienta José de Souza Martins, pelo "partido" do Governo, que cumpre um destacado papel na mediação dos interesses das elites locais e de segmentos do poder central, conseguindo capturar os objetivos e prioridades dos programas de desenvolvimento endereçados as áreas menos dinâmicas, constituindo-se num dos pilares do denominado "poder do atraso" em nosso país.

No Brasil e em outras partes do mundo o desenvolvimento de uma região depende, também, da capacidade de seus habitantes atuarem como "grupo de pressão" sobre a esfera federal, estadual, municipal, e de agirem eficazmente no sentido de atrair investimentos públicos e privados. A localização da capital na cidade do Rio de Janeiro e o conseqüente afluxo para ela de elites de outras partes do país teria criado no centro econômico e político do Estado do Rio de Janeiro o que alguns autores denominaram de "mentalidade cosmopolita". Tais comportamentos se traduzem num grande interesse pelos problemas globais do país e no total descaso pelos interesses estritamente regionais e locais. Na prática, isto significa renúncia a disputar com outros estados os grandes investimen- 
tos públicos e privados que constituem o cerne dos processos de desenvolvimento regional e local.

Com relação à fusão Rio de Janeiro-Guanabara, em si um projeto recomendável, não foi implementado com as devidas precauções pelo regime autoritário, interessado em obter rápidos dividendos políticos decorrentes de medidas promulgadas por Atos Complementares à Constituição Federal. É conveniente mencionar, que o antigo Distrito Federal, por acumular tributos municipais e estaduais, era uma unidade federativa relativamente rica, que proporcionava, em consequiência, elevados níveis de atendimento à sua população (saúde, educação, cultura, lazer, etc.) . Em suma, com o advento da fusão, o município do Rio de Janeiro foi obrigado a ceder ao estado importante parcela de sua arrecadação tributária; esse fato, aliado à forte queda do padrão dos serviços oferecidos, gerou sérios problemas financeiros e sociais para o Município do Rio de Janeiro. Por outro lado, sendo este o principal pólo econômico do estado, sua fragilidade representa uma perda significativa para a região.

Pesquisa realizada pela revista Exame, em 1995, mostrou que, à semelhança do Estado de São Paulo, o Rio de Janeiro também conseguiu manter significativas áreas de influência, decorrentes de sua participação em expressivos segmentos da economia brasileira. Assim, no universo de 500 (quinhentas) melhores empresas privadas, apontadas pela Exame, investigamos as 50 (cinqüenta) maiores, selecionadas pelo volume de vendas para todo o país.

\section{TABELA 5}

DEMONSTRATIVO DO VOLUME DE VENDAS POR ESTADO DAS PRINCIPAIS EMPRESAS PRIVADAS DO PAÍS 1995

\begin{tabular}{lcc}
\hline $\begin{array}{l}\text { UNIDADES DA } \\
\text { FEDERAÇÃO }\end{array}$ & $\begin{array}{l}\text { VENDAS (em } \\
\text { US\$ milhões) }\end{array}$ & $\begin{array}{c}\text { PARTICIPAÇÃo } \\
\text { NACIONAL (\%) }\end{array}$ \\
\hline São Paulo & $50.033,8$ & $47 \%$ \\
Rio de Janeiro & $34.973,4$ & $32 \%$ \\
Minas Gerais & $11.335,3$ & $10 \%$ \\
Outras unidades da Federação & $12.108,4$ & $11 \%$ \\
\hline Total & $108.450,9$ & $100 \%$ \\
\hline
\end{tabular}

Fonte: Revista Exame. As Melhores e Maiores, agosto 1995

Organização: Jacob Binsztok

A análise dos dados contidos na Tabela 5 demonstra a supremacia das empresas sediadas em São Paulo, com $47 \%$ do total nacional, com as montadoras (Volkswagen, Ford e General Motors) representando 31\% das vendas das empresas paulistas. 
A segunda posição, obtida pelas empresas sediadas no Estado do Rio de Janeiro, representando $32 \%$ do total nacional, contou com a participação do segmento de distribuição de petróleo (Shell, Esso, Texaco e Atlantic), concentrando $40 \%$ do volume de vendas das empresas fluminenses.

A terceira posição, representada pelo estado de Minas Gerais, com 10\% do total nacional, com 54\% de suas vendas no segmento das montadoras (Fiat), apresentou padrão de concentração, superior às das empresas paulistas e fluminenses.

Os restantes $11 \%$ do total nacional, encontram-se diluídos entre as diversas unidades da federação, respectivamente Rio Grande do Sul, Bahia, Santa Catarina, Distrito Federal, Pernambuco, Amazonas e Espirito Santo.

Apesar dos seus aspectos negativos, o funcionamento da capital do país no estado tinha um ponto bastante positivo: o setor público foi extremamente dinâmico, em termos de investimentos e geração de renda, além de atrair determinados segmentos da iniciativa privada. A transferência da capital para Brasília foi realizada sem qualquer consideração do impacto negativo sobre o Rio de Janeiro do desaparecimento de um dos seus mais dinâmicos setores. Neste sentido, o mínimo que se deveria esperar do Governo Federal seria uma análise deste, e a sugestão de medidas capazes de compensá-lo. No entanto, absolutamente nada foi realizado visando o preenchimento das lacunas deixadas pelo esvaziamento do setor público.

\section{TABELA 6}

DEMONSTRATIVO DO VOLUME DE VENDAS POR ESTADO DAS PRINCIPAIS EMPRESAS ESTATAIS - 1995 -

\begin{tabular}{lcc}
\hline $\begin{array}{l}\text { UNIDADES DA } \\
\text { FEDERAÇÃO }\end{array}$ & $\begin{array}{c}\text { VENDAS (EM } \\
\text { US\$ MILHÕES) }\end{array}$ & $\begin{array}{c}\text { PARTICIPAÇÃO } \\
\text { NACIONAL (\%) }\end{array}$ \\
\hline Rio de Janeiro & $43.965,9$ & $56 \%$ \\
São Paulo & $16.050,1$ & $20 \%$ \\
Distrito Federal & $4.613,1$ & $6 \%$ \\
Minas Gerais & $3.552,7$ & $4,5 \%$ \\
Outras unidades da federação & $10.158,2$ & $13,5 \%$ \\
\hline Total & $78.340,5$ & $100 \%$ \\
\hline
\end{tabular}

Fonte: Revista Exame; As Melhores e Maiores, ago. 1995.

Organização: Jacob Binsztok

Analisando a Tabela 6 constatamos a supremacia do Estado do Rio de Janeiro no setor das empresas estatais, comercializando, em 1995, 44 bilhões de dólares e atingindo 56\% do total nacional. A Petrobrás, alcançando 21 bilhões, e a Petrobrás Distribuidora, com 8 bilhões e 600 milhões de dólares, foram responsáveis, respectivamente, por $47 \%$ e $19 \%$ do total nacional. A segunda posição do setor coube ao 
estado de São Paulo, com 16 bilhões de dólares, representando $20 \%$ do total nacional. A Eletropaulo, com 5 bilhões de dólares e a Telesp, com 3 bilhões, atingiram, respectivamente, $31 \%$ e $15 \%$ do total estadual.

O recrudecimento das propostas neoliberais, colocadas em prática pelo Governo FHC, via Programa Nacional de Privatização e outras medidas, além de proporcionar maciças transferências de recursos públicos para o setor privado, principalmente para conglomerados do tipo Bozano Simonsen, Norberto Odebrecht, Gerdau, Garantia, Vicunha e outros, também, irá provocar significativas mudanças no ranking das empresas estatais no Rio de Janeiro, contribuindo para o "enxugamento" do setor público, exigido pela "base técnica", como condição indispensável para o "ajuste" das contas do governo e conseqüente estabilidade econômica. Tais conglomerados, detentores de numerosos títulos públicos e excedentes financeiros, acumulados nos surtos inflacionários, segundo a lógica ditada pelo modelo, estariam aptos para apropriarem-se de empresas estatais, em função da "competência" e "eficiência" apresentadas por estes setores, ao contrário da propalada "estagnação" demonstrada pelo setor público.

\section{TABELA 7}

DEMONSTRATIVO DO VOLUME DE VENDAS POR ESTADO DAS PRINCIPAIS EMPRESAS PÚBLICAS DO PAÍS - 1995

\begin{tabular}{lcc}
\hline $\begin{array}{l}\text { UNIDADES DA } \\
\text { FEDERAÇÃO }\end{array}$ & $\begin{array}{l}\text { VENDAS (em } \\
\text { US\$ milhões) }\end{array}$ & $\begin{array}{c}\text { PARTICIPAÇÃo } \\
\text { NACIONAL (\%) }\end{array}$ \\
\hline Rio de Janeiro & $78.939,3$ & $42 \%$ \\
São Paulo & $66.083,9$ & $35 \%$ \\
Minas Gerais & $14.888,0$ & $9 \%$ \\
Outras unidades da Federação & $26.879,7$ & $14 \%$ \\
\hline Total & $186.790,9$ & $100 \%$ \\
\hline
\end{tabular}

Fonte: Revista Exame. As Melhores e Maiores, agosto 1995

Organização: Jacob Binsztok

As informações reveladas pela Tabela 7, consignadas pela Exame, reafirmaram a hegemonia do Estado do Rio de Janeiro, comercializando, em 1995, quase 79 bilhões de dólares, seguido do Estado de São Paulo, com 66 bilhões de dólares, ocupando respectivamente $42 \%$ e $35 \%$ do total do país. Estes resultados refletem o dinamismo dos segmentos estatais da economia fluminense, atualmente reestruturados pelas operações do Programa Nacional de Privatizações, empenhadas na transferência de significativas parcelas de recursos públicos para o domínio de consórcios empresariais privados nacionais e internacionais. Neste particular, é relevante assinalar a capacidade gerencial demonstrada pelos grandes conglomerados nacionais, que rapidamente ajustaram-se aos requisitos preconizados pelos 
rentiers das finanças internacionais, no preenchimento dos espaços ocupados pelas empresas estatais sediadas no Estado do Rio de Janeiro.

Paralelamente às medidas destinadas ao "enxugamento" do setor público, o Governo Federal incentivou a viabilização de projetos que, ditados pelos padrões neoliberais, produzirão profundas alterações econômicas, determinando a ocorrência de um processo de "reestruturação" do espaço no Estado do Rio de Janeiro.

Como principais sinalizadores do processo de "reestruturação" do espaço fluminense, também difundidos como eventos precursores da "recuperação" econômica do Estado do Rio de Janeiro, podemos realçar os seguintes projetos: (1) fábrica de caminhões da Volkswagen, em Resende, com investimentos de 300 milhões de dólares; (2) expansão do Porto de Sepetiba, em Itaguaí, com aplicação de US\$ 178 milhões do BNDES, para a construção de um terminal de grãos e dois terminais de carga geral e conteineres, além, ainda, de US\$170 milhões aplicados nas obras de super-estrutura das instalações portuárias; (3) construção do Teleporto, na área central da cidade do Rio de Janeiro, bancado pela municipalidade, ao custo de US\$ 150 milhões, com a finalidade de abrigar departamentos de telemática de grupos empresariais nacionais e estrangeiros.

Como um dos paradigmas desta "reestruturação", podemos mencionar, ainda, o projeto Iridium/Motorola, maior fabricante mundial de celulares que, aproveitando-se de condições como: "flexibilização" do monopólio das telecomunicações, aprovado pelo Congresso Nacional e infra-estrutura em telecomunicações e interconexões com a rede pública, apontou o Rio de Janeiro como a melhor localização física para a instalação da primeira Gateway (estação terrestre) para a América do Sul (Mercosul). Assim, o referido conglomerado decidiu investir US\$ 100 milhões, na implementação desta estação, junto ao complexo da EMBRATEL em Guaratiba, centralizando as atividades do sistema Iridium Mundial para toda a América do Sul no Estado do Rio de Janeiro. O governo estadual concedeu incentivos fiscais ao projeto, pois a empresa só pagará $20 \%$ do valor do ICMS (Imposto sobre Circulação de Mercadorias e Serviços) quando os serviços forem instalados, os restantes $80 \%$ sendo pagos só daqui a seis anos, com uma pequena correção que ainda será estipulada.

Comentando o processo de "reestruturação" do espaço fluminense, o geógrafo Pedro Pinchas Geiger, embora não ponderando o papel representado pelos padrões do neoliberalismo, salientou o caráter "pioneiro" das iniciativas promovidas pelo Governo Estadual, na orientação do planejamento para as questões pertinentes ao desequilíbrio regional interno, destacando que:

... É interessante, pois, fazer o paralelo com o que se observa na atuação do governo de Marcelo Alencar, que vem se empenhando pela atração de investimentos externos, públicos (governo federal, agências internacionais) e privados (Volkswagen e outros) e elege, como prioridade, um programa para o desenvolvimento de uma região, designada de Baixada Fluminense e Municípios Adjacentes, o Pró-Baixada. 
Existem também grandes diferenças em relação aos casos anteriores. A primeira é que, neste caso, se trata de iniciativa estadual. Durante o regime militar, o planejamento se encontrava centralizado na esfera federal. Havia planos de desconcentração para "pólos de crescimento", “cidades médias”, "regiões polarizadas”, mas não de descentralização. Naquele tempo, seguindo o modelo, o governo do estado de São Paulo dividiu seu território em regiões, para fins administrativos, e de desconcentração da capital. No entanto, salvo melhor informação, o caso do Rio de Janeiro seria o primeiro, depois da democratização, a mostrar uma esfera estadual que se orienta para a questão da desigualdade regional interna. (Jornal do Brasil, 23/11/95, p. 7)

As análises destes projetos não confirmaram os comentários feitos por Pedro P. Geiger, ao contrário, revelaram a presença de "alianças", entre segmentos empresariais e políticos fluminenses que, mediados pelo Governo Federal, nos moldes da "modernização" conservadora, elaboraram uma série de eventos visando a formação de "nichos" modernizantes, contando, inclusive, com o aporte de vultosos recursos públicos (via BNDES, incentivos Estaduais, Municipais, etc...) inserindo determinadas áreas na denominada globalização dos mercados, forma de imperialismo, incentivado por entidades vinculadas ao capital internacional, como o FMI e o Banco Mundial.

Logo, os referidos "nichos" atuariam no incremento do Mercosul, dentro dos marcos neoliberais, contribuindo para "liberar" as empresas do "corporativismo" existente nos portos do Rio de Janeiro e de Santos, deliberadamente sucateados, a partir do final dos anos 80, facilitando, ainda, a transferência da atividade industrial para áreas não atingidas pelos movimentos reivindicatórios dos sindicatos organizados, como no caso do $\mathrm{ABCD}$, seguindo recomendação de Mário Henrique Simomsen, um dos mais expressivos líderes do pensamento conservador no país.

Como efeitos colaterais do processo de modernização da estrutura produtiva e da disseminação de novos padrões tecnológicos e organizacionais, decorrentes do desmantelamento do fordismo e do taylorismo, substituídos pelo toyotismo, fomentado pela lógica da globalização dos mercados, deverão se acentuar na economia fluminense os impactos produzidos pelo desemprego, pela precarização, pela concentração de renda, pela regressão dos direitos sociais, pelo debilitamento da representação sindical e pelo desmonte da rede de proteção social.

\section{Crise e a construção da unidade dialética entre o urbano e $o$ agrário fluminense}

Os impactos proporcionados pela adoção do receituário neoliberal encontrarão, no Estado do Rio de Janeiro, um quadro bastante fragilizado pelo declínio da economia do país na última década. Conforme demonstram os dados da Tabela 8, a Região Metropolitana do Rio de Janeiro apresentou o aumento mais significativo 
da proporção de pobreza do setor urbano do país, contrastando com a performance obtida pelos indicadores do PIB e de renda per capita estaduais, explicitadas nas Tabelas 1 e 2 .

\section{TABELA 8}

PRECARIZAÇÃO DAS REGIÕES METROPOLITANAS (1981-1990)

\begin{tabular}{lcc}
\hline REGIÕES & \multicolumn{2}{c}{ PROPORÇÃO DE POBREZA URBANA (\%) } \\
METROPOLITANAS & $\mathbf{1 9 8 1}$ & $\mathbf{1 9 9 0}$ \\
\hline Belém & 50,9 & 43,2 \\
Fortaleza & 54,0 & 41,3 \\
Recife & 55,6 & 47,4 \\
Salvador & 43,1 & 38,0 \\
Belo Horizonte & 31,3 & 29,6 \\
Rio de Janeiro & 27,2 & 32,2 \\
São Paulo & 22,0 & 21,6 \\
Curitiba & 17,4 & 12,2 \\
Porto Alegre & 17,9 & 20,9 \\
\hline Total & $\mathbf{2 9 , 1}$ & $\mathbf{2 8 , 9}$ \\
\hline
\end{tabular}

Fonte: Rocha e Tolosa, "Núcleo-Periferia Metropolitana: Diferenciais de Renda e Pobreza", São Paulo: INAE, Forum Nacional, maio 1993.

Reorganização: Jacob Binsztok

A precarização e a incapacidade da Região Metropolitana do Rio de Janeiro em absorver novos contigentes migratórios, foram assinaladas por Wilson Cano da seguinte forma:

O Rio de Janeiro, desde a década de sessenta, já dava sinais da deterioração de qualidade da vida urbana e da perda da capacidade de continuar como grande receptor de migrantes nacionais. Isto escancarava, cada vez mais, o elevado grau de miséria, pobreza e criminalidade dessa região. (CANO 1994: 594)

Comentando a situação da Região Metropolitana do Rio de Janeiro, Jane Santos de Oliveira (1993) aproxima-se dos geógrafos Ariovaldo Umbelino de Oliveira, Milton Santos e Roberto Lobato Corrêa, mostrando que a tão decantada "inchação" urbana não pode ser responsabilizada pela pobreza metropolitana, ao assinalar que:

A trajetória observada no Rio de Janeiro é especialmente grave dados o seu tamanho demográfico (10,0 milhões de habitantes, segundo o Censo de 1991) e sua importância 
econômica. O empobrecimento do Rio de Janeiro se deve claramente aos efeitos combinados da crise recessiva e da perda progressiva de seu papel econômico. Fica descartado o habitual argumento de "inchamento populacional", já que a metrópole apresentou durante a última década um crescimento demográfico médio inferior ao crescimento vegetativo da população brasileira (respectivamente 1,0\% e 1,9\% ao ano). (OLIVEIRA 1993:35)

Alertando para a necessidade de uma interação entre as questões de políticas públicas e de renda, a autora ressalta:

Cabe lembrar que, como pobreza não se restringe à insuficiência de renda, mas depende, em muitos casos, de acesso a serviços públicos, como saneamento básico, a situação de pobreza metropolitana no Brasil é especialmente grave porque combina insuficiência de renda a elevados déficits de infra-estrutura social, cuja oferta é essencial para garantir condições mínimas de vida em ambientes de alta densidade de ocupação. (OLIVEIRA, 1993:35)

Com respeito aos trabalhos geográficos, que nos interessam mais particularmente, e que não estão sendo objeto da recente preocupação da mídia, verificamos que os mesmos, de há muito, já se manifestavam preocupados, registrando uma série de observações referentes às condições sociais da população e dos impactos ambientais decorrentes da ocupação predatória do espaço agrário fluminense. Neste sentido, o diagnóstico da Baixada Fluminense feito por Orlando Valverde pode ser considerado emblemático desta questão:

Mais ilustrativo da complexa interação do homem com o meio é o exemplo da Baixada Fluminense, trecho da Baixada Litorânea, situado no Estado do Rio. Essa região era ocupada, desde os tempos de Colônia até o fim do império, por fazendas que produziam, principalmente, farinha de mandioca, açúcar mascavo e aguardente. Com o desenvolvimento industrial e comercial do Rio de Janeiro e da lavoura do café no Vale do Paraíba, ocorreu o seu despovoamento. $O$ abandono das fazendas culminou com a abolição da escravatura. Desaparecendo a navegação fluvial e sem limpeza os leitos dos rios foram-se entulhando de sedimentos, a ponto de alguns desaparecerem, transbordando-se em brejos que se tornariam terríveis focos de malária. A exploração dessas terras passou então a ser perigosa para a saúde e antieconômi$\mathrm{ca}$, até a época em que, desenvolvida a técnica de saneamento, o governo empreendeu a dragagem dos rios e a erradicação da malária. Hoje, algumas várzeas são aproveitadas para a produção de verduras e as terras mais altas, enxutas e arenosas são ocupadas por laranjais...(VALVERDE, 1963: 25)

E continua Valverde, comentando o caráter especulativo do uso da terra em algumas áreas da Baixada Fluminense, afirmando que:

... Perto do Rio de Janeiro e ao longo das principais estradas, as terras voltaram a ser inaproveitadas agricolamente, não mais por imposição do meio. $O$ crescimento excessivo da cidade e a inflação levaram a uma forma de especulação da terra que é o loteamento urbano, 
para sítios de repouso, chácaras, etc. No meio das capoeiras baixas e dos laranjais, abrem-se arruamentos e erguem-se cartazes de anúncios de venda de terras.

Veja-se bem, pela descrição acima, que a exploração da Baixada Fluminense era feita antigamente por uma técnica primitiva. A perda da mão-de-obra, de que dependia essa técnica, desorganizou a economia regional. Só quando o governo, dispondo de novos recursos, tornou a modificar o meio e pôde instalar uma nova estrutura fundiária: pequenas propriedades com hortas, propriedades médias e grandes com laranjais e latifúndios em loteamentos.

(VALVERDE, 1963: 25)

A manipulação política exercida pelo poder público decorrente da realização de obras do Departamento Nacional de Obras e Saneamento (DNOS), incorporando novas terras, não passa despercebida pelos geógrafos, mostrando novamente:

... caso da Baixada Fluminense, cujo saneamento tornou-se uma das obras mais caras e de maior propaganda durante o chamado Estado Novo (1937-1945), depois de ter-se tornado pantanosa e palúdica, após anos de uso indevido dos seus solos...(ANDRADE, 1979: 104)

A importância exercida pela Região Metropolitana do Rio de Janeiro, nas articulações com o espaço agrário do estado nos anos oitenta, foi analisada pelos geógrafos entre os quais Britto e Inocêncio (1987) que, numa retrospectiva histórica, assim ressaltaram o fato:

Tem sido particularmente destacado o papel da cidade do Rio de Janeiro que, a partir do Século XVIII, vem influenciando de modo marcante a evolução do setor agropecuário estadual. Numa primeira fase, que se estendeu até as primeiras décadas do Século XX, essa metrópole atuou basicamente como pólo dinamizador do setor rural, contribuindo para que a agricultura do estado atingisse projeção máxima no País durante a expansão cafeeira no vale do Paraíba. Na fase mais recente bem caracterizada a partir da década de 50, a cidade do Rio de Janeiro desenvolveu formas de articulação bem mais complexas com o meio rural fluminense, verificando-se, inclusive, a importância de sua atuação no sentido do esvaziamento da agricultura e do agravamento das questões sociais no campo.

(BRITTO E INOCÊNCIO, 1987: 115)

A persistência de uma produção camponesa em algumas áreas da Região Metropolitana do Rio de Janeiro, articulada e submetida aos interesses do capital urbano, complementando as observações feitas por Valverde (1963), foi registrada pelos autores, mostrando que:

... Essa valorização torna, em certas áreas, o preço das terras pouco compatível com a prática da agricultura realizada com perspectiva de continuidade, a não ser que seja desenvolvida através de formas de exploração caracterizadas por alta rentabilidade. A pequena produção persiste, é verdade, mesmo no Município do Rio de Janeiro, onde se constata o 
valor médio das terras mais elevado do País, mas é aí desenvolvida freqüentemente por produtores - ocupantes e assume caráter provisório, mantendo-se apenas enquanto os proprietários aguardam momento oportuno para a venda das terras.

(BRITTO E INOCÊNCIO, 1987: 115)

Logo, a região Metropolitana do Rio de Janeiro, com seus dez milhões e 500 mil habitantes, dos quais 3,6 milhões vivendo abaixo da linha de pobreza, é hoje o retrato presente e futuro das grandes aglomerações urbanas e acima de tudo da permanente crise com que se defronta o espaço agrário do país e especificamente do caso fluminense, envolvidos pelas diferentes formas de expansão capitalista da renda da terra urbana e rural, que de maneira decisiva contribuem para a manutenção do atual quadro de degradação social que marca as cidades brasileiras.

Com respeito às especificidades do espaço agrícola fluminense, é importante registrar que o Estado do Rio de Janeiro é um dos menores estados da federação, possuindo apenas $43.000 \mathrm{~km}^{2}$, o equivalente a 0,5 do território nacional. Contudo, sua população atinge 13,0 milhões de habitantes, o que representa quase $10 \%$ da população brasileira, com uma densidade demográfica de $320 \mathrm{ha} / \mathrm{km}^{2}$, que é a mais elevada do país.

A distribuição deste contingente é extremamente desigual, pois cerca de $92 \%$ da população está concentrada nas cidades, ostentando o maior índice de urbanização do país, com apenas $8 \%$ do efetivo ocupando o meio rural, portanto muito abaixo da média nacional, que é de $28 \%$ da população no campo.

Em termos de demanda, estudos da extinta Comissão Estadual de Planejamento Agrícola destacaram o fato de que, além da presença do grande mercado consumidor representado pela Região Metropolitana, cabe destacar ainda a proximidade do mercado paulista, para o qual se orienta parte da produção hortícola fluminense, através de fornecimento de produtos obtidos em áreas de clima quente e úmido ou de safras sazonalmente alternadas. Contudo, a grande proximidade dos maiores mercados metropolitanos brasileiros não parece ter induzido a modernização e intensificação do setor, exceto em segmentos da produção olerícola, avícola ou, em casos pontuais, da pecuária leiteira. A proximidade do mercado produtor de São Paulo, ao que tudo indica, parece ter contribuído para tornar desfavoráveis as condições de competitividade.

Do ponto de vista das condições naturais, não há motivos para considerar o espaço agrário do estado sem perspectivas de desenvolvimento. Assim, o caráter montanhoso de grande parte do território não deve ser considerado apenas como fator limitante, pois permite uma variação climática não contemplada pela latitude. $\mathrm{O}$ aluvionamento nos alvéolos intramontanos favorece as práticas agrícolas, e nas encostas não demasiadamente íngremes a lavoura pode ser realizada com os necessários procedimentos conservacionistas. Existe abundância de cursos d'água, o que viabiliza projetos de irrigação e de energia, embora deva se controlar eventu- 
ais prejuízos para outros usos; nas regiões planas da baixada litorânea, obras de drenagem podem permitir o acréscimo de grandes extensões de terra arável.

Outras áreas, como as remanescentes agrícolas da Região Metropolitana e certas áreas da Região Serrana, menos dotadas que as planícies aluviais, também se prestam à ocupação agrícola ou pecuária, requerendo, para elevação substancial de sua produtividade, aplicação de tecnologias apropriadas, em particular quanto à recuperação dos solos, esgotados ou degradados por usos predatórios.

Existe, portanto, uma série de condições geográficas favoráveis a uma expansão do desenvolvimento agrícola, uma atividade cuja importância não é necessário enfatizar. Note-se que o setor privado, com apoio governamental, mantém ainda uma posição de destaque nacional para o estado em alguns produtos, em termos de valor e volume, como por exemplo, na produção de tomate, chuchu e pimentão.

Com respeito às questões referentes à utilização de mão-de-obra no setor agrícola, é relevante destacar que os últimos levantamentos censitários não comprovaram a expansão da denominada "pecuarização", ou seja, não ocorreu a difundida tese da substituição de lavouras por pastagens, como também não aumentou a atração exercida pela Região Metropolitana do Rio de Janeiro, fatores geralmente apontados por alguns autores como geradores de um hipotético "êxodo rural" no campo fluminense.

Segundo estimativas oficiais, a mão-de-obra empregada pelo setor está em torno de 300 mil pessoas, representando cerca de $8 \%$ da população economicamente ativa, com uma produtividade média reconhecidamente baixa, correspondendo a $1 \%$ do produto interno bruto do Estado do Rio de Janeiro.

Com relação às disponibilidades de capital, é interessante ressaltar que, embora não haja dúvidas em relação à existência de recursos financeiros no pólo metropolitano do Rio de Janeiro, o setor agrário parece não ter conseguido exercer a respectiva atração no sentido de captar parcela significativa desses excedentes. Assim, alguns segmentos interessados no estudo dos problemas do agrofluminense, justificam os motivos para a lentidão dos investimentos, explicitando-os da seguinte forma: a descapitalização da agricultura tradicional, as limitações de ordem física pertinente à atividade, parecem ter contribuído para reduzir o interesse dos capitais urbanos e emoldurar um quadro típico de estagnação envolvendo a agropecuária do Estado. Contudo, instrumentos creditícios ofertados até período recente, forte apoio dos governos Federal e Estadual e uma certa melhoria da infraestrutura rural, notadamente dos sistemas de escoamento e comercialização, iniciaram um processo de "modernização conservadora", comum também em outros pontos do país, e que proporcionou significativas mudanças no setor agropecuário do Rio de Janeiro.

Com respeito aos procedimentos adotados pelo ajuste neoliberal no agro fluminense, podemos constatar, que os mecanismos de reconversão da renda capitalista da terra, já utilizados em diversos pontos do país, também estão aptos para atuar no estado, principalmente na Área Açucareira de Campos, como comprovam 
as recentes desapropriações feitas nas usinas Victor Sense e São João. As grandes fazendas do Vale do São João, ocupando vastas extensões não aproveitadas nos municípios de Casimiro de Abreu e Silva Jardim, também deverão ser incluídas no processo de reconversão da renda capitalista da terra, pois, à semelhança de Campos, os empresários do Vale são bastante influentes na composição das "alianças" que sustentam o atual pacto político do país. No entanto, é conveniente lembrar que as tentativas para a reconversão da renda da terra não deverão ficar restritas aos estabelecimentos localizados no Vale do São João ou na Baixada Campista, podendo ocorrer, inclusive, em outras áreas do estado, como na Região do Médio Paraíba, nas Baixadas Litorâneas e até mesmo nas proximidades da Região Metropolitana do Rio de Janeiro, onde encontraremos grandes proprietários capitalistas de terra vizinhos de acampamentos montados pelos trabalhadores vinculados ao MST/RJ.

Para Ariovaldo Umbelino de Oliveira, os movimentos reformistas no campo aparecem no capitalismo como uma necessidade conjuntural do sistema de atenuar as pressões sociais advindas da concentração de terras, além de encobrir negócios altamente lucrativos envolvendo o pagamento de desapropriações para fins de Reforma Agrária. Assim, concordamos com o geógrafo quando constatamos que as indenizações pagas pelo INCRA sofreram uma sobrevalorização em média de $115 \%$ acima do preço de mercado, como no caso da Fazenda do Salto, localizada em Barra Mansa, possibilitando a reconversão de ativos financeiros retidos na terra em dinheiro disponível para o capitalista proprietário de terra. Nesta perspectiva, podemos afirmar com o autor que a luta pela terra não pode ficar restrita apenas à luta pelo direito de acesso à terra, devendo ser travada contra quem está encobrindo a propriedade capitalista da terra, ou seja, o capital.

As avaliações sobrevalorizadas feitas pelo INCRA, manipulando o mercado de terras em diversas unidades da federação, inclusive no espaço agrário fluminense, foram objeto de investigações do Ministério Público, comprovando o óbvio funcionamento de um pacto privilegiando os grandes capitalistas de terra, que por intermédio de mediações políticas, participaram ativamente das indicações dos dirigentes regionais do INCRA. Em nossa opinião, foram formados "anéis" de pressão envolvendo dirigentes regionais do INCRA e grandes proprietários de terras, interessados na obtenção de compensações financeiras aos grupos que desmobilizaram ativos protegidos anteriormente como reserva de valor e atualmente corroídos pelo ajuste promulgado pela estabilização conservadora.

Os mecanismos de reconversão da renda da terra também contemplaram os grandes proprietários capitalistas com o pagamento de juros compensatórios estipulados em $12 \%$, recentemente reduzidos para $6 \%$, complementados por juros de mercado, computados enquanto correm os processos na Justiça, acrescidos, ainda, de compensações oferecidas pelas benfeitorias e coberturas florestais existentes nas propriedades. 
A dimensão política assumida pelo ajuste neoliberal pode ser retratada pelas contradições do Governo FHC que, apesar do conteúdo modernizante dos discursos oficiais, enquadrou-se perfeitamente nos tradicionais sistemas de "alianças" vigentes no país. Neste sentido foi construído um pacto envolvendo de um lado, lideranças comprometidas com o ideário liberal e "tecnopolíticos" afinados com as diretrizes do Consenso de Washington e, de outro, representativos segmentos oligárquicos, corroborando as teses de José de Sousa Martins sobre a permanente cooptação destes setores como forma de manutenção da estabilidade política do país. As mediações feitas pelas "alianças" que sustentaram o prosseguimento do ajuste neoliberal no Governo FHC estão na raiz das compensações financeiras concedidas aos grandes proprietários capitalistas nas desapropriações realizadas pelo INCRA, sinalizando, ainda, novas modalidades para a reconversão da terra comandada pelo Estado, em consonância com as exigências da reestruturação do desenvolvimento capitalista no país.

Por último, em nossa opinião, o exame das relações de trabalho no espaço agrário fluminense, é considerado indispensável para o entendimento dos movimentos contraditórios e desiguais, decorrentes da própria capacidade do desenvolvimento capitalista em criar e recriar relações de trabalho capitalistas e não capitalistas no campo. Nesta perspectiva, verificamos os amplos espaços ocupados pelas relações de trabalho familiar, típicas das unidades de produção camponesa, combinando o avanço do empreendimento capitalista, como no caso do Vale do São João, e a expansão do campesinato, representado pelas lutas do MST, presentes em diferentes pontos do espaço agrário do Estado do Rio de Janeiro. Os recentes embates promovidos pelo MST, além de sinalizarem a formação de uma aliança entre trabalhadores rurais e urbanos reunificando a dicotomia entre o campo e a cidade, também podem ser interpretados como focos de resistência contra a proletarização mantidos pelos trabalhadores expropriados, que procuraram na abertura da posse o espaço necessário para o resgate da unidade de produção camponesa. A "escravidão" tradicionalmente denunciada pela mídia como restrita aos longínquos empreendimentos rurais da Amazônia e do Centro-Oeste, enfatizada, portanto, pela dimensão "regional", também reaparece no espaço agrário fluminense, recriada pelo desenvolvimento capitalista em Fazendas do Sul do estado e em propriedades do município de Rio Bonito, comprovando a presença do trabalho escravo, inclusive em áreas beneficiadas pelo processo de modernização tecnológica do campo brasileiro. Com respeito à flexibilização e à precarização das relações de trabalho no meio rural, denúncias feitas pela CPT/RJ, comprovaram, ainda, a superexploração da mão-deobra infantil na área açucareira de Campos, introduzida não pela via camponesa, mas pela "terceirização", decantada em prosa e verso nas sofisticadas orientações neoliberais adotadas pelos dirigentes da política econômica do país. 
CRISE E CONSTRUÇÃO DE UMA NOVA ORDEM TERRITORIAL NO ESTADO DO RIO DE JANEIRO

Resumo: Um quadro de crise que se arrasta no tempo no plano estadual tem origem na longa e artificial separação entre a cidade do Rio de Janeiro e sua região polarizada. Em função dela se define a estrutura territorial atual e a equação que aponta para uma nova ordem territorial para o Estado.

Palavras-chave: Esvaziamento econômico, Políticas territoriais, Ordenamento territorial.

CRISIS AND CONSTRUCTION OF A NEW TERRITORIAL ORDER IN THE STATE OF RIO DE JANEIRO

Summary: A condition of crisis, since much time on the State of Rio de Janeiro, begins with the large and artificial partition between Rio de Janeiro city and its polarized region. At this condition is defined the present territorial structure and the equation that points to a new territorial order for the State.

Keywords: Economic emptying, Territorial politics, Territorial arrangement.

\section{BIBLIOGRAFIA}

ANDRADE, Manuel Correia de (1979): Agricultura e Capitalismo. São Paulo: Liv. Ed. Ciências Humanas.

BINSZTOK, Jacob (1994): Capitalismo Autoritário e a Questão Ambiental no Espaço Agrário do Estado do Rio de Janeiro. Tese defendida no Concurso de Professor Titular de Geografia Humana do Departamento de Geografia da Universidade Federal Fluminense. Niterói.

(1997): O Espaço Agrário Fluminense: ideologia, desenvolvimento, contradições e desigualdades. Tese de Doutoramento em Geografia Humana no Departamento de Geografia da Universidade de São Paulo. São Paulo.

(1998): Capitalismo Autoritário e a Questão Ambiental no Espaço Agrário no Vale do São João. In: Campo Aberto, o rural no Estado do Rio de Janeiro. Organização Maria José Carneiro et al. Rio de Janeiro: Contra Capa Livraria.

EVANGELISTA, Hélio, GRABOIS, José (1993): $O$ Vale do São João numa abordagem ambiental. Comunicação apresentada no $5^{\circ}$ Congresso sobre a Universidade e o Meio Ambiente, UFMT, Cuiabá.

BRITTO, Maria A., INOCÊNCIO, Nei Rodrigues (1987): Organização do espaço agrário no Estado do Rio de Janeiro. Revista Brasileira de Geografia, v. 50, n. 3.

LIMONAD, E. (1996): Os lugares da Urbanização. S. Paulo, USP: Tese de Doutoramento.

MARTINS, J. S. (1994): O poder do atraso. S. Paulo: HUCITEC.

OLIVEIRA, Ariovaldo Umbelino de (1988): O campo brasileiro no final dos anos 80. Boletim Paulista de Geografia, n. 66.

OLIVEIRA, Jane Santos (1993): O traço da desigualdade social no Brasil. Rio de Janeiro: FIBGE.

VALVERDE, Orlando (1963): Metodologia da geografia agrária. In: Geografia Agrária do Brasil. Rio de Janeiro: CBPE/INEP/MEC. 